\title{
Targeting Nrf2 may reverse the drug resistance in ovarian cancer
}

\author{
Danjie $\mathrm{Li}^{1}$, Xiaoling Hong ${ }^{1}$, Feijie Zhao ${ }^{1}$, Xinxin $\mathrm{Ci}^{2^{*}}$ and Songling Zhang ${ }^{1 *}$ (B)
}

\begin{abstract}
Background: Acquired resistance to therapeutic drugs has become an important issue in treating ovarian cancer. Studies have shown that the prevalent chemotherapy resistance (cisplatin, paclitaxel etc.) for ovarian cancer occurs partly because of decreased production of reactive oxygen species within the mitochondria of ovarian cancer cells.

Main Body: Nuclear erythroid-related factor-2 ( $\mathrm{Nr}$ 2) mainly controls the regulation of transcription of genes through the Keap1-Nrf2-ARE signaling pathway and protects cells by fighting oxidative stress and defending against harmful substances. This protective effect is reflected in the promotion of tumor cell growth and their resistance to chemotherapy drugs. Therefore, inhibition of the Nrf2 pathway may reverse drug resistance. In this review, we describe the functions of Nrf2 in drug resistance based on Nrf2-associated signaling pathways determined in previous studies.
\end{abstract}

Conclusions: Further studies on the relevant mechanisms of Nrf2 may help improve the outcomes of ovarian cancer therapy.

Keywords: Nrf2, Drug resistance, Reactive oxidative stress, Ovarian cancer

\section{Background}

Malignant ovarian tumors are one of the most common malignant tumors of the female reproductive organ. Among them, ovarian epithelial cancer has the highest mortality rate, posing a serious threat to women's life. Early stage ovarian tumors are usually located deep inside the pelvis, exhibit no typical symptoms and are thus discovered only at the advanced stage. The treatment options for advanced ovarian cancer are usually cytoreductive surgery and chemotherapy. However, the current chemoresistance in ovarian cancer $(\mathrm{OC})$ has become a key cause of treatment failure and OC-related deaths [1]. Although extensive research has been carried out on complex factors, including increased drug efflux, drug inactivation, alteration in drug target, and increased

\footnotetext{
*Correspondence: cixinxin@jlu.edu.cn; slzhang@jlu.edu.cn

${ }^{1}$ Department of Obstetrics and Gynecology, The First Hospital of Jilin University, Changchun, China

${ }^{2}$ Institute of Translational Medicine, The First Hospital of Jilin University, Changchun, China
}

DNA repair, the existing mechanisms fail to completely account for the drug resistance in OC $[2,3]$. In recent years, the level of oxygen species (ROS) has also been reported to play a vital role in the development of drug resistance in $\mathrm{OC}$, and thus targeting ROS levels may be a promising strategy to conquer cancer chemoresistance.

Oxidative stress refers to the process of oxidative damage caused by an imbalance between the production and scavenging of oxygen free radicals in the body or cells, resulting in the accumulation of ROS and RNS in the body or cells. Increased ROS levels activate relevant signaling pathways, inhibit the function of tumor suppressor genes, and induce oncogenic mutations, ultimately leading to tumorigenesis $[4,5]$. Moreover, the significance of elevated ROS lies in facilitating genomic instability and DNA damage in tumors with drug resistance and recurrence $[6,7]$. Consequently, more researches on ROS regulation would assist us to overcome drug resistance in OC.

$N r f 2$ exerts a modifying influence on cellular oxidative stress response. At the same time, by modulating the 
expression of antioxidant genes, Nrf2 can help prevent cell damage from ROS and electrophiles and keep the balance of intracellular redox homeostasis $[8,9]$. Conversely, findings from previous studies suggest that continuous activation of antioxidant Nrf2 may be beneficial to the growth of cancer cells, and may become a way for cancer cells to escape the attack of chemotherapy drugs, providing conditions for cancer cells to develop drug resistance [7, 10-12]. Accordingly, the purpose of this review is to review recent research on Nrf2-related drug resistance and mechanisms in $\mathrm{OC}$ to provide reference for clinical treatment.

\section{Nrf2 and ROS}

\section{ROS regulation in OC}

Recently, several studies showed that the generation of ROS is associated with drug resistance [13-16]. On the one hand that ROS mediate cytotoxicity induced by drugs in tumor cells. On the other hand ,cancer cells are surrounded by antioxidant molecules to keep ROS in the tumor microenvironment (TME), which contributes to the maintenance of drug resistance in OC [17]. This phenomenon may be caused by the different concentrations of ROS in cancer cells [18]. Usually, at low levels, ROS stimulate cell proliferation and survival in the form of mitogens $[19,20]$. At medium levels, ROS may hinder the cell cycle process at varying degrees and induce cell differentiation [21]. At high levels, ROS might impair fundamental cellular substances such as proteins, DNAs, RNAs, and cause gene mutations-inhibition of tumor suppressor genes(P53,PTEN)and activation of oncogenes $(K$-ras, $E R K, A K T)$, resulting in tumorigenesis in normal cells or multidrug resistance in cancers [18]. Consistently, Meng et al. and Dharmaraja et al. have identified that platinum-resistant $\mathrm{OC}$ cells can maintain steady high levels of ROS, which results in DNA damage [13, 22, 23]. In addition, several studies have indicated that in the TME, hypoxia-induced ROS cause cisplatin resistance by downregulating $p$-Drp1 (Ser637) and $M f n 1$ in OC cells $[15,16]$. Common radio- and chemotherapeutic agents affect tumor outcome by modulating ROS; therefore, the impact of ROS modulation is essential for cancer treatment.

\section{Nrf2 regulation in $\mathrm{OC}$}

$N r f 2$ is a member of the Cap-n-Collar (CNC) regulatory protein family and is a transcription factor with a highly conserved basic leucine zipper structure. $N r f 2$ is a regulatory protein containing seven domains, Neh1-7, and has diverse features (Fig. 1). The Neh1 domain consists of the $C N C$-bZIP region, in which DNA binds to $s M a f$ proteins as Nrf2 dimerization partners [24, 25]. The Neh2 domain contains two sites, namely DLG and ETGE, which combine with the cytoplasmic protein Keap1, a negative regulator of Nrf2 transcriptional activity [26]. Neh3-5 can bind to coactivating factors and are transactivating structural domains of Nrf2 [27, 28]. Neh6 is a serine-rich region associated with the negative regulation of $N r f 2$ stability, which relies on Keap1 [29]. Neh7 containing the retinoid $\mathrm{X}$ receptor inhibits the transcriptional activity of Nrf2 [30].

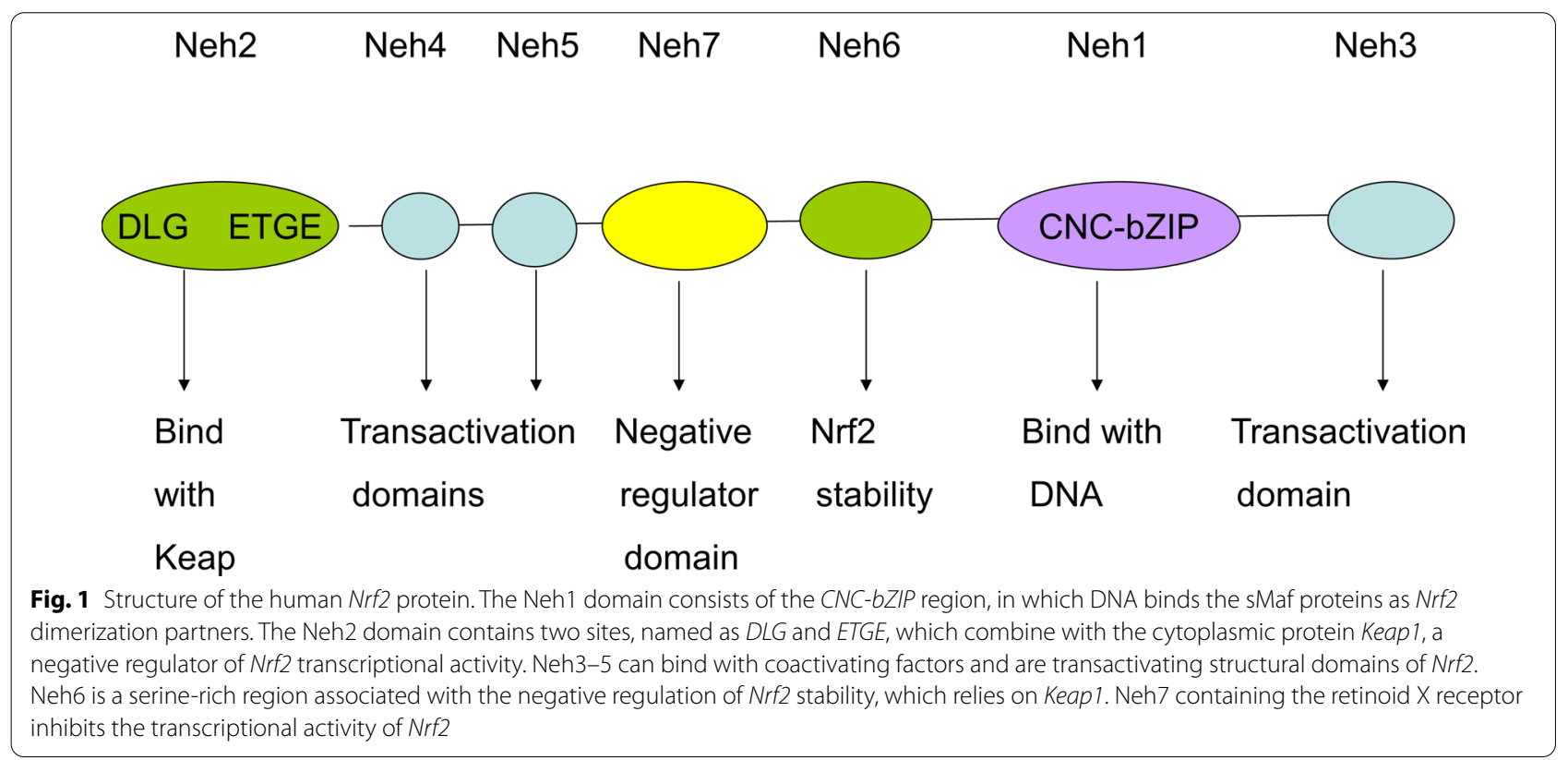


Under physiological conditions, Nrf2 is anchored in the cytoplasm by Keap1 as a substrate for the cullin 3-dependent E3 ubiquitin ligase complex and can induce ubiquitination and promptly degrade Nrf2 via the proteasome. However, when ROS or electrophiles attack cells, Nrf 2 detaches from Keap 1 and is rapidly translocated into the nucleus, forming a heterodimer with the $s M a f$ protein and then integrating with the $A R E$, thereby transcriptionally activating $N r f 2$-regulated antioxidant gene expression including $\mathrm{HO}-1, \mathrm{NQO1}, \mathrm{GCL}, \mathrm{PRDX}$ and $\mathrm{SOD}$ to exert anti-oxidative effects (Fig. 2). Nrf2 has a short half-life of around 10-30 min, and thus the high turnover of Nrf2 induced by Keap 1 maintains ultra-low levels of Nrf2 [31,32]. The protein products of these genes mediate detoxification through glutathione coupling and participate in ATP-dependent drug efflux, which may be involved with cisplatin resistance in OC [33]. High levels of $\mathrm{Nrf} 2$ provide a protective environment in both normal and cancer cells.

Excessive activation of $\mathrm{Nrf2}$ is considered as an intermediate link in cell proliferation and causes drug resistance in cancer therapy as well [34-36]. To be specific,
Nrf2 activation and Keap1 inactivation mutations are the precursors of permanent constitutive activation of the Nrf2-dependent AR pathway, which is frequently observed in cancer. Besides, anti-cancer radiation and chemotherapies, rely heavily on the production of ROS to induce cytotoxicity [37-39]. Hence, excessive activation of the Nrf2-dependent AR pathway will reduce the effectiveness of such treatments [40, 41].

A clinical study has indicated that high cytoplasmic $N r f 2$ expression (the inactivated form of Nrf2) in serous carcinoma subtypes is associated with longer survival $(\mathrm{p}<0.05)$, which appears to correlate with high ER $\alpha$ expression $(\mathrm{p}<0.05)$ [42]. The same team found that Nrf2 expression in the cytoplasm was positively correlated with PR expression $(\mathrm{p}<0.05)$ [43]. Furthermore, a retrospective study of the relationship between $\mathrm{Nrf2}$ expression and clinical prognosis in 108 patients with different subtypes of OC showed that a high expression of Nrf2 in OC indicates short DFS (HR: 2.084; 95\% CI: 1.229-3.536) and OS (HR: 2.487; 95\% CI: 1.443-4.286) [44]. Konstantinopoulos et al. found that among 64 advanced EOC patients, the upregulation of Nrf2 promoted cisplatin
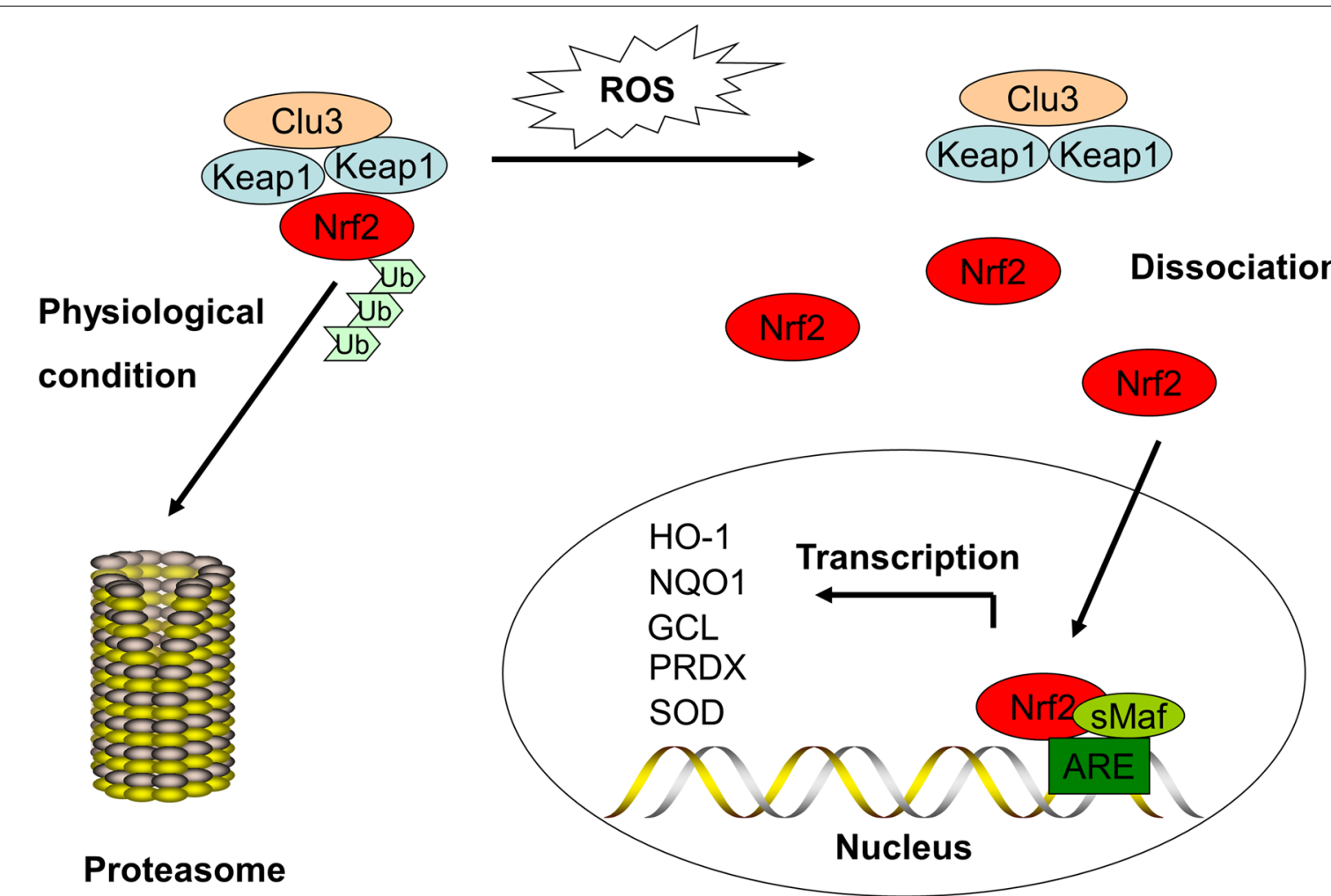

Fig. 2 The classical view of Nrf2 activation and response. Under physiological conditions, Nrf2 is anchored in the cytoplasm by Keap1 as a substrate for Cullin 3-dependent E3 ubiquitin ligase complex and can induce ubiquitination and promptly degrade Nrf2 via the proteasome. However, when ROS or electrophiles attack cells, Nrf2 detaches from Keap1 and is rapidly transferred into the nucleus, forming a heterodimer with the sMaf protein and then integrating with the ARE, thereby transcriptionally activating Nrf2-regulated antioxidant gene expression including $H O-1, N Q O 1, G C L, P R D X$ and $S O D$ to exert anti-oxidative effects 
resistance in $\mathrm{OC}$ patients and was associated with a short OS $(\mathrm{P}<0.05)[45]$. However, another study showed that chemoresistance is not significantly correlated with Nrf2 expression, although patients with low Nrf2 expression have higher recurrence rates and death rates than patients with high Nrf2 expression. [46] Hence, further studies on the relationships between clinical prognosis and Nrf2 expression, as well as relevant drug resistance mechanisms related to $N r f 2$, are needed.

\section{Effect of Nrf2 on treatments for OC}

Oncogenic mutations in OC may promote drug resistance by activating $N r f 2$

Disorder of Nrf2/Keap1 caused by mutation and activation of up-stream oncogenes is associated with nuclear transportation and constitutive activation of Nrf2. Gina et al. have confirmed that oncogenic mutations in primary murine cells, such as Kras, Braf and Myc, separately increased the constitutive transcription of Nrf2 to stabilize the basal Nrf2 level and hence reduce intracellular ROS, ultimately causing cells to escape from apoptosis and promoting tumorigenesis, metastasis and chemoresistance $[9,47]$. In view of the relationship of ROS and $N r f 2$ with tumorigenesis, $N r f 2$ appears to be a significant target for cancer treatment.

\section{Role of $\mathrm{Nrf2}$ in ROS-mediated therapy resistance in OC Role of Nrf2 in ROS-mediated cisplatin resistance in $O C$}

As mentioned earlier, ROS play an indispensable role in the development of drug resistance. As the main antioxidant regulator, $N r f 2$, which is involved in ROS detoxification, tightly regulates drug resistance of tumors. It has been reported that during oxidative stress, as the transcription target of $N r f 2, p 62 / S Q S T M 1$ competes with Nrf2 for binding to Keap1 and forms a positive feedback loop between $p 62$ and $N r f 2$ [48]. Xia et al. showed that overexpressed $p 62$ may protect cells from vitamin K3-induced ROS generation by up-regulating antioxidant genes downstream of $\mathrm{Nrf2}$, including $\mathrm{HO}-1$ and $\mathrm{NQO}$, in OC [49]. Additionally, recent cases reported by Wu et al. also support the hypothesis that overexpression of CD99, a significant downstream gene of $N r f 2$, facilitates $N r f 2-$ mediated cisplatin resistance in OC $[50,51]$. Bao et al. suggested that low levels of $N r f 2$ suppressed the expression of $A B C F 2$ and enhanced cisplatin sensitivity in $\mathrm{OC}$ cells by mediating the drug efflux pump mechanism [52]. Chen et al. argued that knockdown of Nrf2 in the SKVO3 cell line increased the production of ROS induced by cisplatin by increasing the phosphorylation level of $p 38$ $J N K$.This subsequently led to elevation of ATF2 levels, followed by decreased expression of $A K R 1 C 1$, which is involved in apoptosis, ultimately promoting the sensitivity of OC to cisplatin [53]. It was recently reported that activation of $\mathrm{Nrf} 2$ promotes activation of its downstream gene $A K R 1 C 1$, which converts progesterone to an inactive form and promotes platinum resistance in ovarian cancer, while metformin reverses this process by increasing PR expression [54]. Mechanistically, Sun et al. found that SIRT5 contributes to the cisplatin resistance of OC by inhibiting cisplatin-mediated DNA damage via ROS through Nrf2 pathway modulation [55]. SLC40A1, as a novel iron metabolism-associated gene, serves as the only iron exporter gene with several putative Nrf2 binding sites. Wu et al. found that $N r f 2$ is highly expressed in cisplatin-resistant OC cells. Significantly increased gene expression of SLC401, a transferrin that inhibits $\mathrm{Nrf2}$ translocation into the nucleus, reverses iron overloadinduced cisplatin resistance in OC cells [56].

\section{Molecular factors involved in Nrf2 regulation contribute to paclitaxel resistance}

Paclitaxel is a first-line adjuvant drug for the treatment of OC, but only about half of OC patients respond to it $[57,58]$. It is a new anti-microtubule drug that promotes tubulin polymerization to inhibit depolymerization, keeps tubulin stable, and inhibits cell mitosis. These different mechanisms cause a cascade of toxic effects in OC, such as the reduction of $\Delta \psi m$ or elevation of ROS, which will eventually lead to cell death [59]. Enhancing the sensitivity of $\mathrm{OC}$ patients to paclitaxel is of great significance to improve prognosis. Stimulation of $N A D P H$ oxidase to accumulate ROS is an important part of paclitaxel cytotoxicity in cancer cells $[60,61]$. Woo et al. held the view that inhibition of Nrf2 can enhance the chemosensitivity of cancer cells to paclitaxel [62]. We have reason to believe that targeting Nrf2 levels in OC cells may play an important role in overcoming paclitaxel resistance.

\section{Role of Nrf2 in ROS-mediated PARP inhibitor sensitivity in OC}

At present, under the condition of platinum resistance in OC, PARPi have shown encouraging effects in the first [63-65] and second-line [66, 67] maintenance therapy for patients with $B R C A 1 / 2$ mutation and $H R D$ [68]. Cells with HRD must depend on the replaceable mechanisms of NHEJ and $B E R$, both of which require PARP enzymes [69]. BRCA1/2 mutant cancer cells may develop PARPi resistance by restoring $H R$ repair and/or protecting replication forks [70].

Mitochondrial metabolism and ROS production cause DNA oxidative damage and genomic instability in cancers [71]. HRD OCcells require high levels of NAD + and ATP to power PARP-dependent DNA repair [72]. Besides, some scholars have found that PARPi enhanced the effect of Nrf2 inhibitors in BRCA1-mutant OC cells without fear of side effects from the combination of $\mathrm{Nrf} 2$ inhibitors with chemotherapeutics [73]. From the above 
findings, we can speculate that Nrf2 may play an irreplaceable role in PARPi repair of ROS-DNA oxidative damage.

\section{Role of Nrf2 in ROS-mediated pertuzumab and trastuzumab resistance in $O C$}

Several studies have proved that HER2/HER3, Nrf2,and ROS play a key role in promoting growth and drug resistance in cancer cells [74-79]. Specifically, as a key regulator of the Nrf2 pathway, ROS can regulate the HER2/ HER3 complex and activate its function. When pertuzumab and trastuzumab, which target HER2/HER3 receptors, are used to treat with OC cell lines, Nrf2 inhibition suppress the $\mathrm{Nrf2}$-dependent antioxidant response pathway, thereby allowing $\mathrm{OC}$ cells to overcome resistance to monoclonal antibodies. Khalil et al. proved that $N r f 2$ is a key factor driving the drug resistance in OC; this provides a new treatment idea in the sensitization of $\mathrm{OC}$ to immune targeted therapy [80].

Nrf2 inhibition increases the sensitivity of OC cells to adriamycin, one of the chemicals used in the treatment of OC [81]. Besides, Nrf2 modulates the sensitivity of OC cells to lapatinib and erlotinib by regulating the HER 1 receptor [82].

\section{Role of Nrf2 in ROS-mediated Mppa-PDT resistance in OC}

PDT is a new type of tumor treatment method that has emerged in response to the development of medicine. It uses a photosensitizer that specifically accumulates in tumor tissues-currently, Mppa has a wide range of clinical application prospects due to its good absorption, high energy density, and strong permeability [83, 84]. It is activated under a specific wavelength of light, and a complex photochemical reaction occurs to generate ROS, which lead to irreversible tumor damage [85-87]. According to a previous research, $N r f 2$ silencing enhanced PDT sensitivity in breast, colon, renal, and glioblastoma cancer cells based on Mppa, which can increase the accumulation of photosensitizers by down-regulating $A B C G 2$, thereby promoting the production of ROS [88]. Coincidentally, Tian et al. found that the inhibition of Nrf2- ABCG2 / $H O-1$ signaling increased $\mathrm{ROS}$ levels by attenuating antioxidants or pumping Mppa out of OC cells-suggesting that Nrf2-ABCG2 signaling might be involved in the intrinsic resistance to Mppa-PDT [89].

\section{Role of Nrf2 in ROS-mediated ferroptosis resistance in OC}

Ferroptosis is a novel mode of cell death first discovered by Dixon et al. in 2012 that is,-associated with unique morphological structure, biochemical, and genetic manifestations; it is essentially oxidative damage caused by excessive accumulation of iron ion-dependent lipid peroxidation products, mainly mitochondrial alterations
[90]. Under normal conditions, Nrf2 remains inactive; when induced by ROS stimulation or electrophile substances, Nrf2 changes its molecular conformation and activates downstream antioxidant enzymes to play the role of an antioxidant and inhibit cellular ferroptosis [91]. There are two pathways to synthesize glutathione, which plays an essential role in combating oxidative stress, reducing lipid peroxidation, and protecting tissue cells, -in tumor cells: (a) The classical XC-system: the key factor is SLC7A11; and (b) Reverse transsulfuration pathway, and the key enzyme in this pathway is $C B S$; The above pathways can be activated by the ability of GPx4 to specifically convert highly toxic lipid hydrogen peroxide to non-toxic lipid alcohols, breaking down hydrogen peroxide to water, and its inactivation can induce excessive production of lipid ROS, which can contribute to ferroptosis. It has been reported that GPx4 is an Nrf2 downstream gene and that Nrf2 upregulation or GPX4 overexpression may be significantly associated with ferroptosis resistance in head and neck cancer, but this has not been confirmed in OC [92, 93]. In addition, Liu et al. showed that in OC, Nrf2 also causes erastin-induced ferroptosis resistance by activating $C B S$ [94].

\section{Natural inhibitors of $\mathbf{N r f 2}$}

Given that Nrf2 has a protective effect on tumors and can cause chemotherapy resistance, in recent years, many chemical substances and plant extracts have been reported to inhibit $N r f 2$ to confront the problem of drug resistance [95-100].

Brusatol, a quassinoid compound derived from Brucea javanica, is considered as a general translation inhibitor that results in decreased levels of short-lived proteins including Nrf2 [95]. For this reason, brusatol's ability to overcome chemoresistance is compromised. Recently, Chen et al. isolated a $p l C S A$-binding peptide from the malaria protein $V A R 2 C S A$, which effectively promotes the binding of brustol to $\mathrm{OC}$, thus overcoming the drawback mentioned above [96]. In addition, Cucci et al. showed that ailanthone from Ailanthus altissima could significantly inhibit the expression of Nrf2 and YAP protein and subsequently inhibit the growth and colony formation of cisplatin-sensitive and cisplatin-resistant OC cells, and exert greater inhibitory effects on the migration of targeted cisplatin-resistant cells [97].

There are also some compounds that have not been proven in OC. Ascorbic acid, an inhibitor of Nrf2, partially restored cell sensitivity to imatinib by down-regulating Nrf2 and reducing the expression of $\gamma$-GCSL and the level of glutathione [98], and increased the sensitivity of HeLa cells to cisplatin and adriamycin [99]. Apigenin, a flavonoid extracted from various vegetables and fruits, inhibits the Nrf2 pathway, thereby making 
doxorubicin-resistant liver cancer cells sensitive to doxorubicin and increasing intracellular doxorubicin [100].

\section{Conclusions}

The Keap1-Nrf2-ARE system is a critical defense mechanism to protect cells from oxidative stress and electrophilic stress. While temporary Nrf2 activation during stress is advantageous for cell proliferation [101], sustained Nrf2 activation in cancer cells confers chemoresistance and aggressive tumorigenic activity, which has deleterious effects on the cancer patients [102-105]. Since $N r f 2$ increases the antioxidant and detoxification capacity of cancer cells, sustained high levels of $\mathrm{Nrf} 2$ activity can enhance therapeutic resistance of cancer cells. Nrf2 also drives metabolic reprogramming and cooperates with other oncogenic pathways to establish cellular metabolic processes that favor cell proliferation.

Most patients with OC treated by chemotherapy, immunotherapy, and molecular targeted therapy eventually develop resistance and show poor outcomes. In fact, there are many proteins that regulate the process of drug resistance in OC; - for example, downregulation of 14-3-3 , a key protein involved in ovarian development and gamete function [106-108], by RNA interference in OC cells results in enhanced sensitivity to cisplatininduced cell death [109]. Meanwhile, multiple isoforms of 14-3-3 protein strongly interact with the cell cycle protein $C D C 25 B$, which is inactivated in $\mathrm{Nrf2}^{-} /^{-}$cells, to regulate cell cycle in oocyte $[110,111]$. Why did we choose to review Nrf2 as a key pivot in the regulation of drug resistance in OC? As described above, Nrf2, as the main regulator of the antioxidant response pathway, has received increasing attention for its significant effect in drug-resistant $\mathrm{OC}$ and thus, may be targeted for treating advanced OC. So far, several Nrf2 inhibitors have been used for overcoming drug resistance in OC. In addition to $N r f 2$ inhibitors, new potential therapeutic targets related to $\mathrm{Nrf2}$ for overcoming drug resistance in OC are being identified (Fig. 3; Table 1). However, the mechanisms of Nrf2-associated drug resistance in

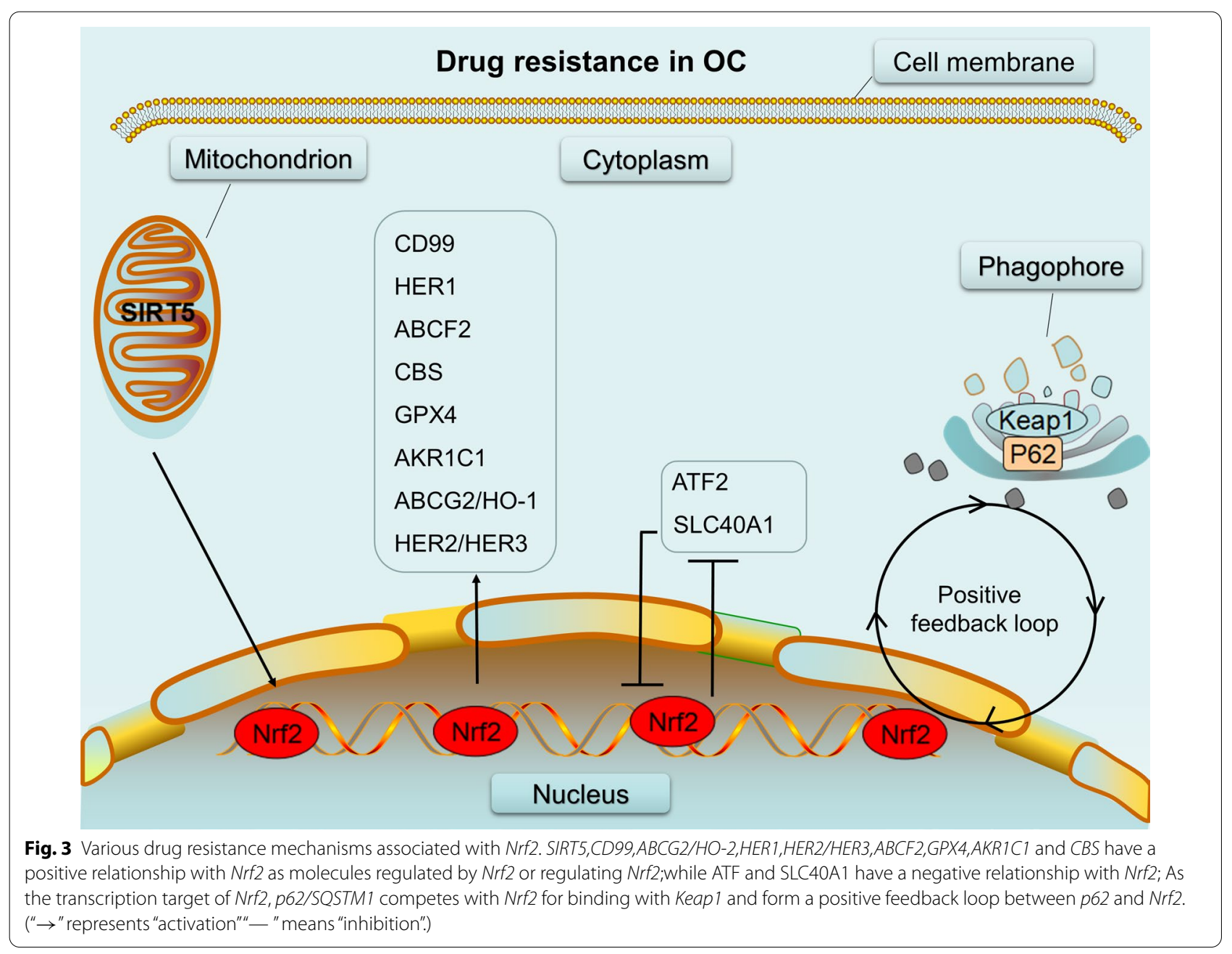


Table 1 Overview of $\mathbf{N r f 2}$-interacting factors in cancer cell lines

\begin{tabular}{|c|c|c|c|c|c|}
\hline Gene & Effects on Nrf2 & Effects on cell & Tumor model & Resistance to & References \\
\hline P62 & Activator & Protective & SKOV3/DDP & Cisplatin & {$[48]$} \\
\hline CD99 & Activator & Protective & A2780,COC1/DDP & Cisplatin & {$[50,51]$} \\
\hline ABCF2 & Activator & Protective & A2780 & Cisplatin & {$[52]$} \\
\hline ATF2 & Inhibitor & Cytotoxic & SKOV3 & Cisplatin & {$[53]$} \\
\hline AKR1C1 & Activator & Protective & - & Platinum & {$[54]$} \\
\hline SIRT5 & Activator & Protective & A2780,SKOV3,CAOV3 & Cisplatin & {$[55]$} \\
\hline SLC40A1 & Inhibitor & Cytotoxic & A2780CP,PEO4,COC1/DDP & Cisplatin & {$[56]$} \\
\hline HER1 & Activator & Protective & PEO1, SKOV3, and OVCAR3 & lapatinib and erlotinib & {$[82]$} \\
\hline HER2/HER3 & Activator & Protective & PEO4,OVCAR4,SKOV3 & Pertuzumab/Trastuzumab/Docetaxel & {$[80]$} \\
\hline $\mathrm{ABCG} 2$ & Activator & Protective & SKOV3 & Mppa-PDT & {$[89]$} \\
\hline GPX4 & Activator & Protective & AMC-HN2-11/SNU & Ferroptosis & {$[92,93]$} \\
\hline CBS & Activator & Protective & SKOV3 and OVCA429 & Ferroptosis & {$[94]$} \\
\hline \multicolumn{6}{|l|}{ Compounds } \\
\hline Brusatol & Inhibitor & Cytotoxic & SKOV3/HEC-1-A/A549 & - & {$[96]$} \\
\hline Ailanthone & Inhibitor & Cytotoxic & A2780/CP70 & Cisplatin & {$[97]$} \\
\hline Ascorbic acid & Inhibitor & Cytotoxic & KCL22/SR; Hela & Imatinib;cisplatin / adriamycin & {$[98,99]$} \\
\hline Apigenin & Inhibitor & Cytotoxic & BEL-7402/ADM & Doxorubicin & [100] \\
\hline
\end{tabular}

OC cells remain unclear and should therefore be further investigated. There is also a need to develop appropriate animal models to evaluate the therapeutic efficacy of Nrf2-related therapeutic targets in drug-resistant OC.

Besides active exploration and mechanistic research on therapeutic targets associated with $\mathrm{Nrf2}$, studies for discovering diagnostic biomarkers and surrogate markers for refractory $\mathrm{OC}$ are also needed. For progress in diagnosis and treatment, further researches and technical improvements are required. Consequently, a thorough elucidation of the function of $\mathrm{Nrf} 2$ will help to improve the clinical diagnosis and prognosis of $\mathrm{OC}$.

\section{Abbreviations}

OC: Ovarian cancer; Nrf2: Nuclear erythroid-related factor-2; Keap-1: Kelch-like ECH-associated protein-1; sMaf: Small musculoaponeurotic fibrosarcoma; ROS: Reactive oxygen species; bZIP: Basic leucine zipper; HO-1: Heme oxygenase 1; NQO1: NAD(P)H dehydrogenase (quinone) 1; ABCG2: ATP-binding cassette, subfamily G, member 2; AKR1C1: Aldo-keto reductase family 1 member C1; SIRT5: Sirtuin 5; SLC40A1: Solute carrier family 40 member 1;TME: Tumor microenvironment; Mppa-PDT: Methyl pyropheophorbide-amediated photodynamic therapy; ABC: ATP-binding cassette; P-gp: P-glycoprotein; PARPi Poly-ADP Ribose Polymerase inhibitors; HRD: Homologous recombination deficiency; CBS: Cystathionine $\beta$-synthase.

\section{Acknowledgements}

We thank Amanda, Editage (www.editage.cn), for English editing a draft of this manuscript.

\section{Authors' contributions}

SZ and XC: conceptualization; DL: writing —original draft preparation; DL,XH and FZ: writing - review and editing; SZ and XC: permission to submit. All authors read and approved the final manuscript.

\section{Funding}

Not applicable.
Availability of data and materials

Not applicable.

Ethics approval and consent to participate

Not applicable.

\section{Consent for publication}

Not applicable.

\section{Competing interests}

All the authors declare no conflict of interest.

Received: 20 November 2020 Accepted: 6 February 2021

Published online: 17 February 2021

\section{References}

1. Capriglione S, Luvero D, Plotti F, et al. Ovarian cancer recurrence and early detection:may HE4 play a key role in this open challenge? A systematic review of literature. Med Oncol. 2017:34:164.

2. Zhong YY, Chen HP, Tan BZ, et al. Triptolide avoids cisplatin resistance and induces apoptosis via the reactive oxygen species/nuclear factor-kB pathway in SKOV3PT platinum-resistant human ovarian cancer cells. Oncol Lett. 2013;6(4):1084-92.

3. Ren F, Shen J, Shi H, et al. Novel mechanisms and approaches to overcome multidrug resistance in the treatment of ovarian cancer. Biochim Biophys Acta. 2016;1866(2):266-75.

4. Sabharwal SS, Schumacker PT. Mitochondrial ROS in cancer: initiators, amplifiers or an Achilles' heel? Nat Rev Cancer. 2014;14(11):709-21.

5. Moloney JN, Stanicka J. T.G. Cotter,Subcellular localization of the FLT3ITD oncogene plays a significant role in the production of NOX-and p22phox-derived reactive oxygen species in acute myeloid leukemia. Leuk Res. 2017:52:34-42.

6. Dharmaraja AT. Role of Reactive Oxygen Species (ROS) in therapeutics and drug resistance in cancer and bacteria. J Med Chem. 2017:60(8):3221-40.

7. Cui Q, Wang J-Q, Assaraf YG, et al. Modulating ROS to overcome multidrug resistance in cancer. Drug Resist Updates. 2018;41:1-25.

8. Latella G. Redox imbalance in intestinal fibrosis: beware of the TGF $\beta-1$, ROS, and Nrf2 connection. Dig Dis Sci. 2018:63(2):312-20. 
9. Sajadimajd S, Khazaei M. Oxidative stress and cancer: the role of Nrf2. Curr Cancer Drug Targets. 2018;18(6):538-57.

10. Alvin JL, Chia CE, Goldring NR, Kitteringham S, Wong Q, Morgan P, Park BK. Differential effect of covalent protein modification and glutathione depletion on the transcriptional response of Nrf2 and NF-kappaB. Biochem Pharmacol. 2010;80(3):410-21.

11. Jaramillo MC, Zhang DD. The emerging role of the Nrf2-Keap1 signaling pathway in cancer. Genes Dev. 2013;27(20):2179-91.

12. Roh J-L, Kim EH, Jang H, Shin D. Nrf2 inhibition reverses the resistance of cisplatin-resistant head and neck cancer cells to artesunate-induced ferroptosis. Redox Biol. 2017;11:254-62.

13. Meng Y, Chen C-W, Mingo MH, Yung. al.DUOXA1-mediated ROS production promotes cisplatin resistance by activating ATR-Chk1 pathway in ovarian cancer. Cancer Lett. 2018;1:104-16.

14. Tonelli C, Chio IIC, Tuveson DA. Transcriptional Regulation by Nrf2. Antioxid Redox Signal. 2018;29:1727-45.

15. Han Y, Kim B, Cho U, et al. Mitochondrial fission causes cisplatin resistance under hypoxicconditions via ROS in ovarian cancer cells. Oncogene. 2019;38(45):7089-105.

16. Li P, Zhang D, Shen L,et al. Redox homeostasis protects mitochondria through accelerating ROS conversion to enhance hypoxia resistance in cancer cells. Sci Rep. 2016;6:22831.

17. Salatino A, Aversa I, Battaglia AM. H-Ferritin affects cisplatin-induced cytotoxicity in ovarian cancer cells through the modulation of ROS. Oxid Med Cell Longev. 2019;2019:3461251.

18. Cui $Q$, Wang JQ, Assaraf YG, et al. Modulating ROS to overcome multidrug resistance in cancer. Drug Resist Updates. 2018;41:1-25.

19. Schieber M, Chandel NS. ROS function in redox signaling and oxidative stress. Curr Biol. 2014;19(10):R453-62.

20. Gill JG, Piskounova E, Morrison SJ. Cancer,oxidative stress, and metastasis. Cold Spring Harb Symp Quant Biol. 2016;81:163-75.

21. Verbon EH, Post JA, Boonstra J. The influence of reactive oxygen species on cell cycle progression in mammalian cells. Gene. 2012;511(1):1-6.

22. Dharmaraja AT. Role of Reactive Oxygen Species (ROS) in therapeutics and drug resistance in cancer and bacteria. J Med Chem. 2017:60(8):3221-40

23. Maiti AK. Gene network analysis of oxidative stress-mediated drug sensitivity in resistant ovarian carcinoma cells. Pharmacogenom J. 2010;10(2):94-104.

24. Tian B, Lu ZN, Guo XL. Regulation and role of nuclear factor-E2-related factor 2 (Nrf2) in multidrug resistance of hepatocellular carcinoma. Chem Biol Interact. 2018;280:70-6.

25. Motohashi H, Katsuoka F, Engel JD, Yamamoto MSmall. Maf proteins serve as transcriptional cofactors for keratinocyte differentiation in the Keap1-Nrf2 regulatory pathway. Proc Natl Acad Sci USA. 2004:101:6379-84.

26. Tong KI, Katoh Y, Kusunoki H, Itoh K, Tanaka T, Yamamoto M. Keap1 recruits Neh2 through binding to ETGE and DLG motifs: characterization of the two-site molecular recognition model. Mol Cell Biol. 2006;26:2887-900.

27. Katoh Y, Itoh K, Yoshida E, Miyagishi M, Fukamizu A, Yamamoto M. Two domains of Nrf2 cooperatively bind CBP, a CREB binding protein, and synergistically activate transcription. Genes Cells. 2001;6:857-68.

28. Nioi P, Nguyen T, Sherratt PJ, Pickett CB. The carboxy-terminal Neh3 domain of $\mathrm{Nrf2}$ is required for transcriptional activation. Mol Cell Biol. 2005;25:10895-906

29. Chowdhry S, Zhang Y, McMahon M, Sutherland C, Cuadrado A, Hayes JD. Nrf2 is controlled by two distinct beta-TrCP recognition motifs in its Neh6 domain,one of which can be modulated by GSK-3 activity. Oncogene. 2013;32:3765-81.

30. Wang H, Liu K, Geng M, Gao P, Wu X, Hai Y,et al. RXRalpha inhibits the NRF2-ARE signaling pathway through a direct interaction with the Neh7 domain of NRF2. Cancer Res. 2013;73:3097-108.

31. Nguyen T, Sherratt PJ, Huang HC, Yang CS, Pickett CB. Increased protein stability as a mechanism that enhances Nrf2-mediated transcriptional activation of the antioxidant response element. Degradation of Nrf2 by the 26 S proteasome. J Biol Chem. 2003;278:4536-41.

32. Motohashi H, O'Connor T, Katsuoka F, Engel JD, Yamamoto M. Integration and diversity of the regulatory network composed of Maf and CNC families of transcription factors. Gene. 2002;294:1-12.
33. Konstantinopoulos PA, Spentzos D, Fountzilas E, Francoeur N, Sanisetty S, Grammatikos AP, et al. Keap1 mutations and Nrf2 pathway activation in epithelial ovarian cancer. Cancer Res. 2011;71(15):5081-9.

34. Gauron C, Rampon C, Bouzaffour M, Ipendey E, Teillon J, Volovitch M, Vris S. Sustained production of ROS triggers compensatory proliferation and is required for regeneration to proceed. Sci Rep. 2013;3:2084.

35. Deeni Y, Khalil HS, Goltsov A, Langdon S, Harrison D, Bown J. Quantitative analysis of proliferation behaviour of ovarian cancer cells with the dynamics of reactive oxygen species production and sequestration. J Biotech. 2014;185:1-126.

36. Khalil HS, Goltsov A, Langdon SP, Harrison DJ, Bown J, Deeni Y. Quantitative analysis of NRF2 pathway reveals key elements of the regulatory circuits underlying antioxidant response and proliferation of ovarian cancer cells. J Biotechnol. 2015;202:12-30.

37. Shibata T, Ohta T, Tong Kl, Kokubu A, Odogawa R, Tsuta K, Asamura H, Yamamoto M, Hirohashi S. Cancer related mutations in NRF2 impair its recognition by Keap1-Cul3 E3 ligase and promote malignancy. Proc Natl Acad Sci USA. 2008;105:13568-73.

38. Ohta T, lijima K, Miyamoto M, Nakahara I, Tanaka H, Ohtsuji M, Suzuki T, Kobayashi A, Yokota J, Sakiyama T, Shibata T, Yamamoto M, Hirohashi S. Loss of Keap1 function activates Nrf2 and provides advantages for lung cancer cell growth. Cancer Res. 2008:68:1303-9.

39. Homma S, Ishii Y, Morishima Y, Yamadori T, Matsuno Y, Haraguchi N, Kikuchi N, Satoh H, Sakamoto T, Hizawa N, Itoh K. Yamamoto Nrf2 enhances cell proliferation and resistance to anticancer drugs in human lung cancer. Clin Cancer Res. 2009;15:3423-32.

40. Pan H, Wang H, Zhu L, Wang X, Cong Z, Sun K, Fan Y. The involvement of Nrf2-ARE pathway in regulation of apoptosis in human glioblastoma cell U251. Neurol Res. 2013;35:71-8.

41. Niture SK, Jaiswal AK. Nrf2-induced antiapoptotic BCl-xL protein enhances cell survival and drug resistance. Free Radic Biol Med. 2013;57:119-31.

42. Czogalla B, Kahaly M, Mayr D, Schmoeckel E, Niesler B, Kolben T, Burges A, Mahner S, Jeschke U, Trillsch F. Interaction of ERa and NRF2 impacts survival in ovarian cancer patients. Int J Mol Sci. 2018;20(1):112.

43. Czogalla B, Kahaly M, Mayr D, Schmoeckel E, Niesler B, Hester A, ZederGöß C, Kolben T, Burges A, Mahner S, Jeschke U, Trillsch F. Correlation of NRF2 and progesterone receptor and its effects on ovarian cancer biology. Cancer Manag Res. 2019;11:7673-84.

44. Liew PL, Hsu CS, Liu WM. Prognostic and predictive values of Nrf2, Keap 1, p16 and E-cadherin expression in ovarian epithelial carcinoma. Int J Clin Exp Pathol. 2015:8:5642-9.

45. Konstantinopoulos PA, Spentzos D, Fountzilas E, et al. Keap1 mutations and Nrf2 pathway activation in epithelial ovarian cancer. Cancer Res. 2011;71(15):5081-9.

46. Cho HY, Kim K, Kim YB, Kim H, No JH. Expression patterns of Nrf2 and Keap1 in ovarian cancer cells and their prognostic role in disease recurrence and patient survival. Int J Gynecol Cancer. 2017;27(3):412-9.

47. DeNicola GM, Karreth FA, Humpton TJ, et al. Oncogene-induced Nrf2 transcription promotes ROS detoxification and tumorigenesis. Nature. 2011:475(7354):106-9.

48. XIA M, YU H, GU S, et al. p62/SQSTM1 is involved in cisplatin resistance in human ovarian cancer cells via the Keap1-Nrf2-ARE system. Int J Oncol. 2014;45(6):2341-8.

49. Xia M, Yan X, Zhou L, XU Y, Su J, Li H. p62 suppressed VK3-induced oxidative damage through Keap1/Nrf2 pathway in human ovarian cancer cells. J Cancer. 2020;11(6):1299-307.

50. Jarboe EA, Hirschowitz SL, Geiersbach KB, Wallander ML, Tripp SR, Layfield $L$, et al. Juvenile granulosa cell tumors: immunoreactivity for CD99 and Fli-1 and EWSR1 translocation status: a study of 11 cases. Int J Gynecol Pathol. 2014;33(1):11-5.

51. Wu J, Zhang Z, Li H, Wu S, Liu Z. Nrf2 Induced Cisplatin Resistance in Ovarian Cancer by Promoting CD99 Expression. Biochem Biophys Res Commun. 2019:518(4):698-705.

52. Bao LJ, Wu JF, Dodson M, Montserrat E, Ning Y, Zhang ZB. et.al.ABCF2, an Nrf2 Target Gene, Contributes to Cisplatin Resistance in Ovarian Cancer. CellsMol Carcinog. 2017;56(6):1543-53.

53. Chen J, Fiona Simpkins SC, Simpkins H. The role of Nrf2 and ATF2 in resistance to platinum-based chemotherapy. Cancer Chemother Pharmacol. 2017;79(2):369-80 
54. Czogalla B, Kahaly M, Mayr D, Schmoeckel E, Niesler B, Hester A, Zeder-Göß C, Kolben T, Burges A, Mahner S, Jeschke U, Trillsch F. Correlation of NRF2 and progesterone receptor and its effects on ovarian cancer biology. Cancer Manag Res. 2019;11:7673-84.

55. Sun X, Wang S, Gai J, Guan J, Li J, Li Y, et al. SIRT5 promotes cisplatin resistance in ovarian cancer by suppressing DNA damage in a ROSdependent manner via regulation of the $\mathrm{Nrf2/HO}-1$ pathway. Front Oncol. 2019;9:754.

56. Wu JF, Bao LJ, Zhang ZB, Yi XF. Nrf2 induces cisplatin resistance via suppressing the iron export related gene SLC40A1 in ovarian cancer cells. Oncotarget. 2017;8(55):93502-15.

57. Ganz PA, Goodwin PJ. Breast cancer survivorship: where are we today? Adv Exp Med Biol. 2015;862:1-8.

58. Anampa J, Makower D, Sparano JA. Progress in adjuvant chemotherapy for breast cancer: an overview. BMC Med. 2015;13:195.

59. Wu J, Neuwelt Y, Leslie AJ, Muldoon L, Neuwelt EA. Acetaminophen enhances cisplatin- and paclitaxel-mediated cytotoxicity to SKOV3 human ovarian carcinoma. Anticancer Res. 2013;33(6):2391-400.

60. Jérôme A, Batteux F, Nicco C, et al. Accumulation of hydrogen peroxide is an early and crucial step for paclitaxel-induced cancer cell death both in vitro and in vivo. Int J Cancer. 2006 Jul;119(1)(1):41-8.

61. Jérôme A, Lu Y, Hu W, Pelicano H, Huang P. Novel action of paclitaxel against cancer cells: bystander effect mediated by reactive oxygen species. Cancer Res. 2007;67(8):3512-7.

62. Woo Y, Oh J, Kim J-S. Suppression of Nrf2 activity by chestnut leaf extract increases chemosensitivity of breast cancer stem cells to paclitaxel. Nutrients. 2017;9(7):760.

63. Moore K, Colombo N, Scambia G, et al. Maintenance Olaparib in patients with newly diagnosed advanced ovarian cancer. N Engl J Med. 2018;379:2495-505.

64. Gonzalez-Martin A, Pothuri B, Vergote I, et al. Niraparib in patients with newly diagnosed advanced ovarian cancer. N Engl J Med. 2019;381:2391-402

65. Ray-Coquard I, Pautier P, Pignata S, et al. Olaparib plus Bevacizumab as first-line maintenance in ovarian cancer. N Engl J Med. 2019;381:2416-28.

66. Ledermann J, Harter P, Gourley C, et al. Olaparib maintenance therapy in platinum-sensitive relapsed ovarian cancer. N Eng J Med. 2012;366:1382-92.

67. Pujade-Lauraine E, Ledermann JA, Selle F, et al. Olaparib tablets as maintenance therapy in patients with platinum-sensitive, relapsed ovarian cancer and a BRCA1/2 mutation (SOLO2/ENGOT-Ov21): a double-blind, randomised, placebo-controlled, phase 3 trial. Lancet Oncol. 2017; 18:1274-84.

68. Tomao F, Bardhi E, Di Pinto A,et al. Parp inhibitors as maintenance treatment in platinum sensitive recurrent ovarian cancer: An updated meta-analysis of randomized clinical trials according to BRCA mutational status. Cancer Treat Rev. 2019;80:101909.

69. Lord CJ, Ashworth A. PARP inhibitors: synthetic lethality in the clinic. Science. 2017;355:1152-8.

70. D'Andrea AD. Mechanisms of PARP inhibitor sensitivity and resistance. DNA Repair. 2018;71:172-6.

71. Sosa V, Moliné T, Somoza R, Paciucci R, Kondoh H, Lleonart ME. Oxidative stress and cancer: an overview. Ageing Res Rev. 2013;12(1):376-90.

72. Lahiguera A, Hyroššová P, Figueras A, et al. Tumors defective in homologous recombination rely on oxidative metabolism: relevance to treatments with PARP inhibitors. EMBO Mol Med. 2020;12(6):e11217.

73. van der Wijst MGP, Huisman C, Mposhi A, Roelfes G, Rots MG. Targeting $\mathrm{Nrf2}$ in healthy and malignant ovarian epithelial cells: Protection versus promotion. Mol Oncol. 2015;9(7):1259-73.

74. Kang HJ, Yi YW, Hong YB,et al. HER2 confers drug resistance of human breast cancer cells through activation of NRF2 by direct interaction. Sci Rep. 2014;4:7201.

75. Manandhar $\mathrm{S}$, Choi $\mathrm{BH}$, Jung KA, et al. NRF2 inhibition represses ErbB2 signaling in ovarian carcinoma cells: implications for tumor growth retardation and docetaxel sensitivity. Free Radic Biol Med. 2012;52:1773-85.

76. Shimokawa H. Reactive oxygen species promote vascular smooth muscle cell proliferation. Circ Res. 2013;113:1040-2.
77. Gauron C, Rampon C, Bouzaffour M, Ipendey E, Teillon J, Volovitch M, Vriz S. Sustained production of ROS triggers compensatory proliferation and is required for regeneration to proceed. Sci Rep. 2013;3:2084.

78. Yang Y, Tian Z, Guo R, Ren F. Nrf2 inhibitor, brusatol in combination with trastuzumab exerts synergistic antitumor activity in HER2-positive cancers by inhibiting Nrf2/HO-1 and HER2-AKT/ERK1/2 pathways. Oxid Med Cell Longev. 2020. https://doi.org/10.1155/2020/9867595.

79. Yang Y, Guo R, Tian X, et al. Synergistic anti-tumor activity of Nimotuzumab in combination with Trastuzumab in HER2-positive breast cancer. Biochem Biophys Res Commun. 2017;489(4):523-7.

80. Hilal S, Khalil SP, Goltsov LA, et al. A novel mechanism of action of HER2 targeted immunotherapy is explained by inhibition of NRF2 function in ovarian cancer cells. Oncotarget. 2016;7(46):75874-901.

81. Manandhar S, Lee S, Kwak M-K. Effect of stable inhibition of NRF2 on doxorubicin sensitivity in human ovarian carcinoma OV90 cells. Arch Pharm Res. 2010;33(5):717-26.

82. Kankia IH, Khalil HS, Simon P. NRF2 Regulates HER1 Signaling Pathway to Modulate the sensitivity of Ovarian Cancer Cells to Lapatinib and Erlotini. Oxid Med Cell Longev. 2017;2017:1864578.

83. Luo T, Wilson BC, Lu Q-B. Evaluation of one- and two-photon activated photodynamic therapy with pyropheophorbide-a methyl ester in human cervical, lung and ovarian cancer cells. J Photochem Photobiol B. 2014;5:102-10.

84. Guelluy P-H, Fontaine-Aupart M-P, Grammenos A, Lécart S, Maryse Hoebeke PJ. Optimizing photodynamic therapy by liposomal formulation of the photosensitizer pyropheophorbide-a methyl ester: in vitro and ex vivo comparative biophysical investigations in a colon carcinoma cell line. Photochem Photobiol Sci. 2010;9(9):1252-60.

85. Stanisław Kwiatkowski BK, Przystupski D, et al. Photodynamic therapymechanisms, photosensitizers and combinations. Biomed Pharmacother. 2018;106:1098-107.

86. Ali M, Rkein DM, Ozog. Photodynamic therapy. Dermatol Clin. 2014 Jul;32(3):415-25. x.

87. David M, Ozog AM, Rkein G, Fabi S, et al. Photodynamic therapy: a clinical consensus guide. Dermatol Surg. 2016;42(7):804-27.

88. Choi BH, Ryoo IG, Kang HC, Kwak MK. The sensitivity of cancer cells to pheophorbide a-based photodynamic therapy is enhanced by Nrf2 silencing. PLoS One. 2014;9:e107158.

89. Tian S, Yong M, Zhu J, et al. Enhancement of the effect of methyl pyropheophorbide-a-mediated photodynamic therapy was achieved by increasing ROS through inhibition of $\mathrm{Nrf2-HO}-1$ or $\mathrm{Nrf2-ABCG2}$ signaling. Anticancer Agents Med Chem. 2017;17:1824-36.

90. Dixon SJ, Lemberg KM, Lamprecht M, et al. Ferroptosis: an iron-dependent form of non-apoptotic cell death. Cell. 2012;149(5):1060-72.

91. Bellezza I, Giambanco I, Minelli A. Nrf2-Keap1 signaling in oxidative and reductive stress. Biochim Biophys Acta. 2018;1865(5):721-33.

92. Doll S, Proneth B, Tyurina YY, et al. ACSL4 ferroptosis sensitivity by shaping cellular lipid. Nat Chem Biol. 2017;13:91-8.

93. Shin D, Kim EH, Lee J, Roh J-L. Nrf2 inhibition reverses resistance to GPX4 inhibitor-induced ferroptosis in head and neck cancer. Free Radic Biol Med. 2018;129:454-62.

94. Nan Liu X, Lin, Huang C. Activation of the reverse transsulfuration pathway through NRF2/CBS confers erastin-induced ferroptosis resistance. Br J Cancer. 2020 Jan;122(2):279-92.

95. Harder B, Tian W, Clair J, Tan AC, Ooi A, Chapman E, et al. Brusatol overcomes chemoresistance through inhibition of protein translation. Mol Carcinog. 2017;56(5):1493-500.

96. Chen X, Yin T, Zhang B, et al. Inhibitory effects of brusatol delivered using glycosaminoglycan-placental chondroitin sulfate A-modified nanoparticles on the proliferation, migration and invasion of cancer cells. Int J Mol Med. 2020;46(2):817-27.

97. Cucci MA, Grattarola M, Dianzani C, Damia G, Ricci F, Roetto A, et al. Ailanthone increases oxidative stress in CDDP-resistant ovarian and bladder cancer cells by inhibiting of Nrf2 and YAP expression through a post-translational mechanism. Free Radic Biol Med. 2020;150:125-35.

98. Tarumoto T, Nagai T, Ohmine K, et al. Ascorbic acid restores sensitivity to imatinib via suppression of Nrf2-dependent gene expression in the imatinib-resistant cell line. Exp Hematol. 2004;32(4):375-81.

99. Wu T-M, Liu S-T, Chen S-Y, Chen G-S, Wu C-C, Huang S-M. Mechanisms and applications of the anti-cancer effect of pharmacological ascorbic acid in cervical cancer cells. Front Oncol. 2020;10:1483. 
100. Gao AM, Ke ZP, Wang JN, Yang JY, Chen SY, Chen H. Apigenin sensitizes doxorubicin-resistant hepatocellular carcinoma BEL-7402/ADM cells to doxorubicin via inhibiting PI3K/Akt/Nrf2 pathway. Carcinogenesis. 2013;34(8):1806-14

101. Motohashi H, Yamamoto M. NRF2-Keap1 defines a physiologically important stress response mechanism. Trends Mol Med. 2004;10:549-557.

102. Romero R, Sayin VI, Davidson SM, et al. Keap1 loss promotes Kras-driven lung cancer and results in dependence on glutaminolysis. Nat Med. 2017;23:1362-1368.

103. Shibata T, Ohta T, Tong Kl, et al. Cancer related mutations in NRF2 impair its recognition by Keap1-Cul3 E3 ligase and promote malignancy. Proc Natl Acad Sci. 2008:105:13568.

104. Shibata T, Kokubu A, Saito S, et al. NRF2 mutation confers malignant potential and resistance to chemoradiation therapy in advanced esophageal squamous cancer. Neoplasia. 2011;13:864-73.

105. Martinez VD, Vucic EA, Thu KL, Pikor LA, Lam S, Lam WL. Disruption of KEAP1/CUL3/RBX1 E3-ubiquitin ligase complex components by multiple genetic mechanisms: association with poor prognosis in head and neck cancer. Head Neck. 2015:37:727-734.

106. De S. The 14-3-3 (YWHA) Proteins in Mammalian Reproduction. Int Ann Sci. 2020;10(1):52-59.
107. Kumrah N, De S. Expression and localization of the 14-3-3 (YWHA) protein family within mammals. NSU Undergraduate Student J. 2020;2020(2)

108. De S, Marcinkiewicz JL, Vijayaraghavan S, et al. Expression of 14-3-3 protein isoforms in mouse oocytes, eggs and ovarian follicular development. BMC Res Notes. 2012;5:57.

109. Kim HJ, Sung SH, Kim CY, Bae MK, Cho MS, Kim YH, Kim SC, Ju W. 14-3$3 \zeta$ overexpression is associated with poor prognosis in ovarian cancer. Yonsei Med J. 2018;59(1):51-6.

110. Eisa AA, De S, Detwiler A, et al. YWHA (14-3-3) protein isoforms and their interactions with CDC25B phosphatase in mouse oogenesis and oocyte maturation. BMC Dev Biol. 2019;19(1):20.

111. Reddy NM, Kleeberger SR, Bream JH, et al. Genetic disruption of the Nrf2 compromises cell-cycle progression by impairing GSH-induced redox signaling. Oncogene. 2008;27(44):5821-32.

\section{Publisher's note}

Springer Nature remains neutral with regard to jurisdictional claims in published maps and institutional affiliations.
Ready to submit your research? Choose BMC and benefit from:

- fast, convenient online submission

- thorough peer review by experienced researchers in your field

- rapid publication on acceptance

- support for research data, including large and complex data types

- gold Open Access which fosters wider collaboration and increased citations

- maximum visibility for your research: over $100 \mathrm{M}$ website views per year

At BMC, research is always in progress.

Learn more biomedcentral.com/submissions 